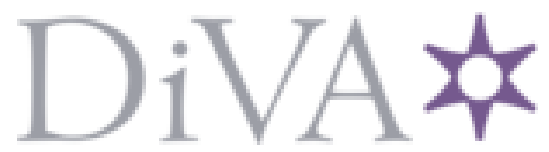

http://www.diva-portal.org

\title{
Postprint
}

This is the accepted version of a paper published in Journal of social service research. This paper has been peer-reviewed but does not include the final publisher proof-corrections or journal pagination.

Citation for the original published paper (version of record):

Salzmann-Erikson, M., Björkman, A. (2017)

Mental illness in the population is increasing: a challenge for telephone advice nurses.

Journal of social service research, 43(3 Special issue): 432

https://doi.org/10.1080/01488376.2016.1248879

Access to the published version may require subscription.

N.B. When citing this work, cite the original published paper.

Permanent link to this version:

http://urn.kb.se/resolve?urn=urn:nbn:se:hig:diva-22899 


\section{Mental illness in the population is increasing - A challenge for telephone advice nurses}

Mental illness is a term that includes everything from mild symptoms of anxiety and depression to more serious mental illnesses such as schizophrenia, depression and suicide. Reports indicate a negative trend, where rates of mental illness in the population are increasing, especially among children and adolescents and among the elderly. This negative trend in Swedish society requires both preventive measures to stem the negative trend but also ongoing community resources to assist, support and advise people with mental illness who seek care.

Vårdguiden's telephone advice line 1177 is a national service that is staffed by nurses and aims to increase Swedish residents' access to care at first contact and as complementary to the Swedish health care centers. Its objective is to offer both quality-insured and user-friendly information as well as services that facilitate contact with health care for both callers and those nearest to the callers. The nurses working at 1177 use a computerized decision support system that is based on the main symptoms presented by the caller. Decision-making support is mainly built around the somatic symptoms of diseases (1). Work life for telephone advice nurses has previously been highlighted in research, and an association between work stress and factors such as lack of time, insufficient clinical experience and the demand for efficiency and performance has been shown (2). The nurses at 1177 are expected to handle between 8-10 calls per hour, and their job performance is recorded through the telephone system and is evaluated on an on-going basis by the management. In previous studies, as an incidental finding on other issues, it emerged that telephone advice nurses described that they are constantly in contact with callers with problems that they are unable to refer further in the health care system and that these nurses experience ethical dilemmas when caller run the risk of "disappearing" within the health care bureaucracy (3) - at the same time, the requirement remains for quality advice on equal terms as for somatic complaints. Despite the increase in mental illness in Swedish society, no studies of the telephone advice line for callers with mental illness could be identified in a search of databases. Research has shown that is extremely important that staff feels that they have adequate knowledge to perform their duties in order to feel security and job satisfaction. Knowledge about the advice nurses' experiences of encountering/giving advice to callers with mental illness is lacking, despite the fact that the 
This is a post-print version of the article "Mental illness in the population is increasing: A challenge for telephone advice nurses" published in Journal of Social Service Research (http://dx.doi.org/10.1080/01488376.2016.1248879) Martin Salzmann-Erikson \& Annica Björkman

patient group is increasing in number. With this letter to the editor, we want to present the idea that people with mental illness should have the same access to equitable, knowledgebased and secure, high-quality health care as those with problems based on physical ailments but also emphasize the challenges it puts on telephone advice nurses.

The author(s) declare that they have no conflict of interests

\section{References}

1. Marklund, B., Ström, M., Månsson, J., Borgquist, L., Baigi, A., \& Fridlund B. (2007) Computer-supported telephone nurse triage: an evaluation of medical quality and costs. Journal of Nursing Management 15, 180-187.

2. Dehghan-nayeri N, Nazari A, Salsali M, Ahmadi F. (2006). To assess role of staffing in nursing productivity: A qualitative research. Hayat, 12, 5-15

3. Holmström, I., \& Höglund, A T. (2007). The faceless encounter: ethical dilemmas in telephone nursing. Journal of Clinical Nursing, 16(10), 1865-1871. 